\title{
Nonlinear conditions for the existence of best proximity points
}

\author{
Wei-Shih Du ${ }^{1 *}$ and Hossein Lakzian²
}

\section{"Correspondence:}

wsdu@nknucc.nknu.edu.tw

'Department of Mathematics,

National Kaohsiung Normal

University, Kaohsiung, 824, Taiwan

Full list of author information is

available at the end of the article

\begin{abstract}
In this paper, we first introduce the new notion of $\mathcal{M T}$-cyclic contraction and establish some new existence and convergence theorems of iterates of best proximity points for $\mathcal{M T}$-cyclic contractions. Some nontrivial examples illustrating our results are also given.

MSC: $41 \mathrm{~A} 17 ; 47 \mathrm{H} 09$

Keywords: cyclic map; best proximity point; $\mathcal{M T}$-function ( $\mathcal{R}$-function); $\mathcal{M T}$-cyclic contraction
\end{abstract}

\section{Introduction and preliminaries}

Throughout this paper, we denote by $\mathbb{N}$ and $\mathbb{R}$ the sets of positive integers and real numbers, respectively. Let $A$ and $B$ be nonempty subsets of a nonempty set $E$. A map $S: A \cup B \rightarrow A \cup B$ is called a cyclic map if $S(A) \subset B$ and $S(B) \subset A$. Let $(X, d)$ be a metric space and $T: A \cup B \rightarrow A \cup B$ be a cyclic map. For any nonempty subsets $A$ and $B$ of $X$, let

$$
\operatorname{dist}(A, B)=\inf \{d(x, y): x \in A, y \in B\} .
$$

A point $x \in A \cup B$ is called to be a best proximity point for $T$ if $d(x, T x)=\operatorname{dist}(A, B)$.

Definition 1.1 ([1]) Let $A$ and $B$ be nonempty subsets of a metric space $(X, d)$. A map $T: A \cup B \rightarrow A \cup B$ is called a cyclic contraction if the following conditions hold:

(1) $T(A) \subset B$ and $T(B) \subset A$;

(2) there exists $k \in(0,1)$ such that $d(T x, T y) \leq k d(x, y)+(1-k) \operatorname{dist}(A, B)$ for all $x \in A$, $y \in B$.

Remark 1.1 Let $A$ and $B$ be nonempty closed subsets of a complete metric space $(X, d)$ and $T: A \cup B \rightarrow A \cup B$ be a cyclic contraction. If $A \cap B \neq \emptyset$, then $\operatorname{dist}(A, B)=0$ and $T$ is a contraction on the complete metric space $(A \cap B, d)$. Hence, applying the Banach contraction principle, we know that $T$ has a unique fixed point in $A \cap B$.

Recently, under some weaker assumptions over a map $T$, the existence, uniqueness and convergence of iterates to the best proximity point were investigated by several authors; see [1-6] and references therein. In [1], Eldred and Veeramani first proved the following interesting best proximity point theorem.

\section{严 Springer}

(c) 2012 Du and Lakzian; licensee Springer. This is an Open Access article distributed under the terms of the Creative Commons Attribution License (http://creativecommons.org/licenses/by/2.0), which permits unrestricted use, distribution, and reproduction in any medium, provided the original work is properly cited. 
Theorem EV ([1, Proposition 3.2]) Let $A$ and B be nonempty closed subsets of a complete metric space $X$. Let $T: A \cup B \rightarrow A \cup B$ be a cyclic contraction map, $x_{1} \in A$ and define $x_{n+1}=T x_{n}, n \in \mathbb{N}$. Suppose $\left\{x_{2 n-1}\right\}$ has a convergent subsequence in $A$. Then there exists $x \in A$ such that $d(x, T x)=\operatorname{dist}(A, B)$.

Let $f$ be a real-valued function defined on $\mathbb{R}$. For $c \in \mathbb{R}$, we recall that

$$
\limsup _{x \rightarrow c} f(x)=\inf _{\varepsilon>0} \sup _{0<|x-c|<\varepsilon} f(x)
$$

and

$$
\limsup _{x \rightarrow c^{+}} f(x)=\inf _{\varepsilon>0} \sup _{0<x-c<\varepsilon} f(x) .
$$

Definition $1.2([7-13])$ A function $\varphi:[0, \infty) \rightarrow[0,1)$ is said to be an $\mathcal{M T}$-function (or $\mathcal{R}$-function) if $\lim \sup _{s \rightarrow t^{+}} \varphi(s)<1$ for all $t \in[0, \infty)$.

It is obvious that if $\varphi:[0, \infty) \rightarrow[0,1)$ is a nondecreasing function or a nonincreasing function, then $\varphi$ is an $\mathcal{M T}$-function. So the set of $\mathcal{M T}$-functions is a rich class.

Very recently, $\mathrm{Du}[10]$ first proved some characterizations of $\mathcal{M T}$-functions.

Theorem $\mathbf{D}([10])$ Let $\varphi:[0, \infty) \rightarrow[0,1)$ be a function. Then the following statements are equivalent.

(a) $\varphi$ is an $\mathcal{M} \mathcal{T}$-function.

(b) For each $t \in[0, \infty)$, there exist $r_{t}^{(1)} \in[0,1)$ and $\varepsilon_{t}^{(1)}>0$ such that $\varphi(s) \leq r_{t}^{(1)}$ for all $s \in\left(t, t+\varepsilon_{t}^{(1)}\right)$.

(c) For each $t \in[0, \infty)$, there exist $r_{t}^{(2)} \in[0,1)$ and $\varepsilon_{t}^{(2)}>0$ such that $\varphi(s) \leq r_{t}^{(2)}$ for all $s \in\left[t, t+\varepsilon_{t}^{(2)}\right]$.

(d) For each $t \in[0, \infty)$, there exist $r_{t}^{(3)} \in[0,1)$ and $\varepsilon_{t}^{(3)}>0$ such that $\varphi(s) \leq r_{t}^{(3)}$ for all $s \in\left(t, t+\varepsilon_{t}^{(3)}\right]$.

(e) For each $t \in[0, \infty)$, there exist $r_{t}^{(4)} \in[0,1)$ and $\varepsilon_{t}^{(4)}>0$ such that $\varphi(s) \leq r_{t}^{(4)}$ for all $s \in\left[t, t+\varepsilon_{t}^{(4)}\right)$.

(f) For any nonincreasing sequence $\left\{x_{n}\right\}_{n \in \mathbb{N}}$ in $[0, \infty)$, we have $0 \leq \sup _{n \in \mathbb{N}} \varphi\left(x_{n}\right)<1$.

(g) $\varphi$ is a function of contractive factor [8]; that is, for any strictly decreasing sequence $\left\{x_{n}\right\}_{n \in \mathbb{N}}$ in $[0, \infty)$, we have $0 \leq \sup _{n \in \mathbb{N}} \varphi\left(x_{n}\right)<1$.

Motivated by the concepts of cyclic contractions and $\mathcal{M T}$-functions, we first introduce the concept of $\mathcal{M T}$-cyclic contractions.

Definition 1.3 Let $A$ and $B$ be nonempty subsets of a metric space $(X, d)$. If a map $T$ : $A \cup B \rightarrow A \cup B$ satisfies

(MT1) $T(A) \subset B$ and $T(B) \subset A$;

(MT2) there exists an $\mathcal{M T}$-function $\varphi:[0, \infty) \rightarrow[0,1)$ such that

$$
d(T x, T y) \leq \varphi(d(x, y)) d(x, y)+(1-\varphi(d(x, y))) \operatorname{dist}(A, B) \quad \text { for any } x \in A \text { and } y \in B,
$$

then $T$ is called an $\mathcal{M T}$-cyclic contraction with respect to $\varphi$ on $A \cup B$. 
Remark 1.2 It is obvious that (MT2) implies that $T$ satisfies $d(T x, T y) \leq d(x, y)$ for any $x \in A$ and $y \in B$.

The following example gives a map $T$ which is an $\mathcal{M T}$-cyclic contraction but not a cyclic contraction.

Example A Let $X=\left\{v_{1}, v_{2}, v_{3}, \ldots\right\}$ be a countable set and $\left\{\tau_{n}\right\}$ be a strictly increasing convergent sequence of positive real numbers. Denote by $\tau_{\infty}:=\lim _{n \rightarrow \infty} \tau_{n}$. Then $\tau_{2}<\tau_{\infty}$. Let $d: X \times X \rightarrow[0, \infty)$ be defined by $d\left(v_{n}, v_{n}\right)=0$ for all $n \in \mathbb{N}$ and $d\left(v_{n}, v_{m}\right)=d\left(v_{m}, v_{n}\right)=\tau_{m}$ if $m>n$. Then $d$ is a metric on $X$. Set $A=\left\{v_{1}, v_{3}, v_{5}, \ldots\right\}, B=\left\{v_{2}, v_{4}, v_{6}, \ldots\right\}$. So $A \cup B=X$ and $\operatorname{dist}(A, B)=\tau_{2}$. Now we define a map $T: A \cup B \rightarrow A \cup B$ by

$$
T v_{n} \stackrel{\text { def }}{=} \begin{cases}v_{2}, & \text { if } n=1, \\ v_{n-1}, & \text { if } n>1\end{cases}
$$

for $n \in \mathbb{N}$. It is easy to see that $T(A)=B$ and $T(B)=A$, and so (MT1) holds. Define $\varphi$ : $[0, \infty) \rightarrow[0,1)$ as

$$
\varphi(t) \stackrel{\text { def }}{=} \begin{cases}\frac{\tau_{n-1}}{\tau_{n}}, & \text { if } t=\tau_{n} \text { for some } n \in \mathbb{N} \text { with } n>2, \\ 0, & \text { otherwise. }\end{cases}
$$

Since $\left\{\tau_{n}\right\}$ is strictly increasing, $\lim \sup _{s \rightarrow t^{+}} \varphi(s)=0<1$ for all $t \in[0, \infty)$. Hence $\varphi$ is an $\mathcal{M T}$-function. Clearly, $\lim _{n \rightarrow \infty} d\left(v_{n}, v_{n+1}\right)=\lim _{n \rightarrow \infty} \tau_{n+1}=\tau_{\infty}$ and $d\left(T v_{1}, T v_{2}\right)=\tau_{2}$. For $m, n \in \mathbb{N}$ with $m>n$ and $m>2, d\left(T v_{n}, T v_{m}\right)=\tau_{m-1}$. So $\lim _{n \rightarrow \infty} d\left(T v_{n}, T v_{n+1}\right)=\lim _{n \rightarrow \infty} \tau_{n}=$ $\tau_{\infty}$. We claim that $T$ is not a cyclic contraction on $A \cup B$. Indeed, suppose that $T$ is a cyclic contraction on $A \cup B$. Thus there exists $k \in[0,1)$ such that

$$
d\left(T v_{n}, T v_{n+1}\right) \leq k d\left(v_{n}, v_{n+1}\right)+(1-k) \operatorname{dist}(A, B) \quad \text { for all } n \in \mathbb{N} .
$$

From (*), we get $\tau_{\infty} \leq \tau_{2}$, which is a contradiction. Therefore, $T$ is not a cyclic contraction on $A \cup B$.

Next, we show that $T$ is an $\mathcal{M T}$-cyclic contraction with respect to $\varphi$. To verify (MT2), we need to observe the following cases:

(i) Since $\varphi\left(d\left(v_{2}, v_{1}\right)\right)=\varphi\left(\tau_{2}\right)=0$, we obtain

$$
\varphi\left(d\left(v_{2}, v_{1}\right)\right) d\left(v_{2}, v_{1}\right)+\left(1-\varphi\left(d\left(v_{2}, v_{1}\right)\right)\right) \operatorname{dist}(A, B)=\tau_{2}=d\left(T v_{1}, T v_{2}\right) ;
$$

(ii) For $m, n \in \mathbb{N}$ with $m>n$ and $m>2$, we have

$$
\begin{aligned}
\varphi\left(d\left(v_{n}, v_{m}\right)\right) d\left(v_{n}, v_{m}\right)+\left(1-\varphi\left(d\left(v_{n}, v_{m}\right)\right)\right) \operatorname{dist}(A, B) & =\varphi\left(\tau_{m}\right) \tau_{m}+\left(1-\varphi\left(\tau_{m}\right)\right) \tau_{2} \\
& >\tau_{m-1}=d\left(T v_{n}, T v_{m}\right) .
\end{aligned}
$$

From above, we can prove that (MT2) holds. Hence $T$ is an $\mathcal{M T}$-cyclic contraction with respect to $\varphi$. Moreover, since $d\left(v_{1}, T v_{1}\right)=\operatorname{dist}(A, B), v_{1} \in A$ is a best proximity point for $T$. 
In this paper, we establish some new existence and convergence theorems of iterates of best proximity points for $\mathcal{M T}$-cyclic contractions. Our results include some known results in the literature as special cases.

\section{Existence and convergence theorems for best proximity points}

First, we establish the following convergence theorem for $\mathcal{M T}$-cyclic contractions, which is one of the main results in this paper.

Theorem 2.1 Let $A$ and $B$ be nonempty subsets of a metric space $(X, d)$ and $T: A \cup B \rightarrow$ $A \cup B$ be an $\mathcal{M T}$-cyclic contraction with respect to $\varphi$. Then there exists a sequence $\left\{x_{n}\right\}_{n \in \mathbb{N}}$ such that $\lim _{n \rightarrow \infty} d\left(x_{n}, T x_{n}\right)=\inf _{n \in \mathbb{N}} d\left(x_{n}, T x_{n}\right)=\operatorname{dist}(A, B)$.

Proof Let $x_{1} \in A \cup B$ be given. Define an iterative sequence $\left\{x_{n}\right\}_{n \in \mathbb{N}}$ by $x_{n+1}=T x_{n}$ for $n \in \mathbb{N}$. Clearly, $\operatorname{dist}(A, B) \leq d\left(x_{n}, x_{n+1}\right)$ for all $n \in \mathbb{N}$. If there exists $j \in \mathbb{N}$ such that $x_{j}=x_{j+1} \in A \cap B$, then $\lim _{n \rightarrow \infty} d\left(x_{n}, x_{n+1}\right)=\inf _{n \in \mathbb{N}} d\left(x_{n}, x_{n+1}\right)=\operatorname{dist}(A, B)=0$. So it suffices to consider the case $x_{n+1} \neq x_{n}$ for all $n \in \mathbb{N}$. By Remark 1.2, it is easy to see that the sequence $\left\{d\left(x_{n}, x_{n+1}\right)\right\}$ is nonincreasing in $(0, \infty)$. Then

$$
t_{0}:=\lim _{n \rightarrow \infty} d\left(x_{n}, x_{n+1}\right)=\inf _{n \in \mathbb{N}} d\left(x_{n}, x_{n+1}\right) \geq 0 .
$$

Since $\varphi$ is an $\mathcal{M T}$-function, applying Theorem $\mathrm{D}$, we get

$$
0 \leq \sup _{n \in \mathbb{N}} \varphi\left(d\left(x_{n}, x_{n+1}\right)\right)<1
$$

Let $\lambda:=\sup _{n \in \mathbb{N}} \varphi\left(d\left(x_{n}, x_{n+1}\right)\right)$. Then $0 \leq \varphi\left(d\left(x_{n}, x_{n+1}\right)\right) \leq \lambda<1$ for all $n \in \mathbb{N}$. If $x_{1} \in A$, then, by (MT1), we have $x_{2 n-1} \in A$ and $x_{2 n} \in B$ for all $n \in \mathbb{N}$. Notice first that (MT2) implies that

$$
\begin{aligned}
d\left(x_{2}, x_{3}\right) & =d\left(T x_{1}, T x_{2}\right) \\
& \leq \varphi\left(d\left(x_{1}, x_{2}\right)\right) d\left(x_{1}, x_{2}\right)+\left(1-\varphi\left(d\left(x_{1}, x_{2}\right)\right)\right) \operatorname{dist}(A, B) \\
& \leq \lambda d\left(x_{1}, x_{2}\right)+\operatorname{dist}(A, B)
\end{aligned}
$$

and

$$
\begin{aligned}
d\left(x_{3}, x_{4}\right) & =d\left(T x_{2}, T x_{3}\right) \\
& \leq \varphi\left(d\left(x_{2}, x_{3}\right)\right) d\left(x_{2}, x_{3}\right)+\left(1-\varphi\left(d\left(x_{2}, x_{3}\right)\right)\right) \operatorname{dist}(A, B) \\
& \leq \varphi\left(d\left(x_{2}, x_{3}\right)\right)\left[\lambda d\left(x_{1}, x_{2}\right)+\operatorname{dist}(A, B)\right]+\left(1-\varphi\left(d\left(x_{2}, x_{3}\right)\right)\right) \operatorname{dist}(A, B) \\
& =\varphi\left(d\left(x_{2}, x_{3}\right)\right) \lambda d\left(x_{1}, x_{2}\right)+\operatorname{dist}(A, B) \\
& \leq \lambda^{2} d\left(x_{1}, x_{2}\right)+\operatorname{dist}(A, B) .
\end{aligned}
$$

On the other hand, if $x_{1} \in B$, then $x_{2 n} \in A$ and $x_{2 n-1} \in B$ for all $n \in \mathbb{N}$. Applying (MT2) again, we also have

$$
d\left(x_{2}, x_{3}\right) \leq \lambda d\left(x_{1}, x_{2}\right)+\operatorname{dist}(A, B)
$$


and

$$
d\left(x_{3}, x_{4}\right) \leq \lambda^{2} d\left(x_{1}, x_{2}\right)+\operatorname{dist}(A, B)
$$

Hence, by induction, one can obtain

$$
\operatorname{dist}(A, B) \leq d\left(x_{n+1}, x_{n+2}\right) \leq \lambda^{n} d\left(x_{1}, x_{2}\right)+\operatorname{dist}(A, B) \quad \text { for all } n \in \mathbb{N} \text {. }
$$

Since $\lambda \in[0,1), \lim _{n \rightarrow \infty} \lambda^{n}=0$. Using (2.1) and (2.2), we obtain $\lim _{n \rightarrow \infty} d\left(x_{n}, x_{n+1}\right)=$ $\inf _{n \in \mathbb{N}} d\left(x_{n}, x_{n+1}\right)=\operatorname{dist}(A, B)$. The proof is completed.

Here we give a nontrivial example illustrating Theorem 2.1.

Example B Let $X=\left\{v_{1}, v_{2}, v_{3}, \ldots\right\}$ be a countable set. Define a strictly decreasing sequence $\left\{\tau_{n}\right\}$ of positive real numbers by $\tau_{n}=\frac{1}{2}+\frac{1}{n}$ for all $n \in \mathbb{N}$. Then $\lim _{n \rightarrow \infty} \tau_{n}=\frac{1}{2}$. Let $d: X \times$ $X \rightarrow[0, \infty)$ be defined by $d\left(v_{n}, v_{n}\right)=0$ for all $n \in \mathbb{N}$ and $d\left(v_{n}, v_{m}\right)=d\left(v_{m}, v_{n}\right)=\tau_{n}$ if $m>n$. Then $d$ is a metric on $X$. Set $A=\left\{v_{1}, v_{3}, v_{5}, \ldots\right\}$ and $B=\left\{v_{2}, v_{4}, v_{6}, \ldots\right\}$. So

$$
\lim _{n \rightarrow \infty} d\left(v_{n}, v_{n+1}\right)=\inf _{n \in \mathbb{N}} d\left(v_{n}, v_{n+1}\right)=\lim _{n \rightarrow \infty} \tau_{n}=\operatorname{dist}(A, B)=\frac{1}{2} .
$$

Let $T: A \cup B \rightarrow A \cup B$ be defined by

$$
T v_{n} \stackrel{\text { def }}{=} v_{n+1} \quad \text { for } n \in \mathbb{N} \text {. }
$$

It is easy to see that $T(A)=B$ and $T(B) \subset A$ and so (MT1) holds. Let $x_{1}=v_{1} \in A$ be given. Define an iterative sequence $\left\{x_{n}\right\}_{n \in \mathbb{N}}$ by $x_{n+1}=T x_{n}$ for $n \in \mathbb{N}$. So $\left\{x_{n}\right\}$ and $\left\{v_{n}\right\}$ are identical, and hence $\lim _{n \rightarrow \infty} d\left(x_{n}, x_{n+1}\right)=\inf _{n \in \mathbb{N}} d\left(x_{n}, x_{n+1}\right)=\operatorname{dist}(A, B)=\frac{1}{2}$. Define $\varphi:[0, \infty) \rightarrow[0,1)$ as

$$
\varphi(t) \stackrel{\text { def }}{=} \begin{cases}\frac{\tau_{n+1}}{\tau_{n}}, & \text { if } t=\tau_{n} \text { for some } n \in \mathbb{N}, \\ 0, & \text { otherwise. }\end{cases}
$$

Since $\lim \sup _{s \rightarrow t^{+}} \varphi(s)=0<1$ for all $t \in[0, \infty), \varphi$ is an $\mathcal{M T}$-function. Now, we verify (MT2). For $m, n \in \mathbb{N}$ with $m>n$, since $\left\{\tau_{n}\right\}$ is strictly decreasing and $\frac{\tau_{n+1}}{\tau_{n}}<1$,

$$
\begin{aligned}
& \varphi\left(d\left(x_{n}, x_{m}\right)\right) d\left(x_{n}, x_{m}\right)+\left(1-\varphi\left(d\left(x_{n}, x_{m}\right)\right)\right) \operatorname{dist}(A, B) \\
& =\tau_{n+1}+\frac{1}{2}\left(1-\frac{\tau_{n+1}}{\tau_{n}}\right) \\
& >\tau_{n+1}=d\left(T x_{n}, T x_{m}\right),
\end{aligned}
$$

which prove that (MT2) holds. Hence $T$ is an $\mathcal{M T}$-cyclic contraction with respect to $\varphi$. Therefore, all the assumptions of Theorem 2.1 are satisfied and the conclusion can follow from Theorem 2.1.

The following best proximity point theorem can be given immediately from Theorem 2.1. 
Theorem 2.2 Let $A$ and $B$ be nonempty subsets of a metric space $(X, d)$ and $T: A \cup B \rightarrow$ $A \cup B$ be a cyclic map. Suppose that there exists a nondecreasing (or nonincreasing) function $\tau:[0, \infty) \rightarrow[0,1)$ such that

$$
d(T x, T y) \leq \tau(d(x, y)) d(x, y)+(1-\tau(d(x, y))) \operatorname{dist}(A, B) \quad \text { for any } x \in A \text { and } y \in B .
$$

Then there exists a sequence $\left\{x_{n}\right\}_{n \in \mathbb{N}}$ such that $\lim _{n \rightarrow \infty} d\left(x_{n}, T x_{n}\right)=\inf _{n \in \mathbb{N}} d\left(x_{n}, T x_{n}\right)=$ $\operatorname{dist}(A, B)$.

Corollary 2.1 ([1]) Let $A$ and $B$ be nonempty subsets of a metric space $(X, d)$ and $T$ : $A \cup B \rightarrow A \cup B$ be a cyclic contraction. Then there exists a sequence $\left\{x_{n}\right\}_{n \in \mathbb{N}}$ such that $\lim _{n \rightarrow \infty} d\left(x_{n}, T x_{n}\right)=\inf _{n \in \mathbb{N}} d\left(x_{n}, T x_{n}\right)=\operatorname{dist}(A, B)$.

Here, we give an existence theorem for best proximity points.

Theorem 2.3 Let $A$ and $B$ be nonempty subsets of a metric space $(X, d)$ and $T: A \cup B \rightarrow$ $A \cup B$ be a cyclic map. Let $x_{1} \in A$ be given. Define an iterative sequence $\left\{x_{n}\right\}_{n \in \mathbb{N}}$ by $x_{n+1}=T x_{n}$ for $n \in \mathbb{N}$. Suppose that

(i) $d(T x, T y) \leq d(x, y)$ for any $x \in A$ and $y \in B$;

(ii) $\left\{x_{2 n-1}\right\}$ has a convergent subsequence in $A$;

(iii) $\lim _{n \rightarrow \infty} d\left(x_{n}, x_{n+1}\right)=\operatorname{dist}(A, B)$.

Then there exists $v \in A$ such that $d(v, T v)=\operatorname{dist}(A, B)$.

Proof Since $T$ is a cyclic map and $x_{1} \in A, x_{2 n-1} \in A$ and $x_{2 n} \in B$ for all $n \in \mathbb{N}$. By (ii), $\left\{x_{2 n-1}\right\}$ has a convergent subsequence $\left\{x_{2 n_{k}-1}\right\}$ and $x_{2 n_{k}-1} \rightarrow v$ as $k \rightarrow \infty$ for some $v \in A$. Since

$$
\operatorname{dist}(A, B) \leq d\left(v, x_{2 n_{k}}\right) \leq d\left(v, x_{2 n_{k}-1}\right)+d\left(x_{2 n_{k}-1}, x_{2 n_{k}}\right) \quad \text { for all } k \in \mathbb{N}
$$

it follows from $\lim _{n \rightarrow \infty} d\left(v, x_{2 n_{k}-1}\right)=0$ and the condition (iii) that $\lim _{n \rightarrow \infty} d\left(v, x_{2 n_{k}}\right)=$ $\operatorname{dist}(A, B)$. By (i), we have

$$
\operatorname{dist}(A, B) \leq d\left(T v, x_{2 n_{k}+1}\right) \leq d\left(v, x_{2 n_{k}}\right) \quad \text { for all } k \in \mathbb{N},
$$

which implies $d(v, T v)=\operatorname{dist}(A, B)$.

Applying Theorems 2.1 and 2.3, we establish the following new best proximity point theorem for $\mathcal{M T}$-cyclic contractions.

Theorem 2.4 Let $A$ and $B$ be nonempty subsets of a metric space $(X, d)$ and $T: A \cup B \rightarrow$ $A \cup B$ be an $\mathcal{M T}$-cyclic contraction with respect to $\varphi$. Let $x_{1} \in A$ be given. Define an iterative sequence $\left\{x_{n}\right\}_{n \in \mathbb{N}}$ by $x_{n+1}=T x_{n}$ for $n \in \mathbb{N}$. Suppose that $\left\{x_{2 n-1}\right\}$ has a convergent subsequence in $A$, then there exists $v \in A$ such that $d(v, T v)=\operatorname{dist}(A, B)$.

Remark 2.1 ([1, Proposition 3.2]) (i.e. Theorem EV) is a special case of Theorem 2.4. 
Authors' contributions

Both authors contributed equally and significantly in writing this paper. Both authors read and approved the final manuscript.

\section{Author details}

'Department of Mathematics, National Kaohsiung Normal University, Kaohsiung, 824, Taiwan. ${ }^{2}$ Department of Mathematics, Payame Noor University, Tehran, 19395-4697, Iran.

\section{Acknowledgements}

The first author was supported partially by the grant No. NSC 100-2115-M-017-001 of the National Science Council of the Republic of China.

Received: 1 June 2012 Accepted: 5 September 2012 Published: 19 September 2012

\section{References}

1. Eldred, AA, Veeramani, P: Existence and convergence of best proximity points. J. Math. Anal. Appl. 323, 1001-1006 (2006)

2. Kirk, WA, Srinivasan, PS, Veeramani, P: Fixed points for mappings satisfying cyclical contractive conditions. Fixed Point Theory 4, 79-89 (2003)

3. Eldred, AA, Anuradha, J, Veeramani, P: On the equivalence of the Mizoguchi-Takahashi fixed point theorem to Nadler's theorem. Appl. Math. Lett. 22, 1539-1542 (2009)

4. Al-Thagafi, MA, Shahzad, N: Convergence and existence results for best proximity points. Nonlinear Anal. 70 3665-3671 (2009)

5. Suzuki, T, Kikkawa, M, Vetro, C: The existence of the best proximity points in metric spaces with the property UC. Nonlinear Anal. 71, 2918-2926 (2009)

6. Jleli, M, Karapinar, E, Samet, B: Fixed point results for almost generalized cyclic $(\psi, \varphi)$-weak contractive type mappings with applications. Abstr. Appl. Anal. 2012, Article ID 917831 (2012). doi:10.1155/2012/917831

7. Du, W-S: Some new results and generalizations in metric fixed point theory. Nonlinear Anal. 73, 1439-1446 (2010)

8. Du, W-S: Nonlinear contractive conditions for coupled cone fixed point theorems. Fixed Point Theory Appl. 2010, Article ID 190606 (2010). doi:10.1155/2010/190606

9. Du, W-S: New cone fixed point theorems for nonlinear multivalued maps with their applications. Appl. Math. Lett. 24 172-178 (2011)

10. Du, W-S: On coincidence point and fixed point theorems for nonlinear multivalued maps. Topol. Appl. 159, 49-56 (2012)

11. Du, W-S: On generalized weakly directional contractions and approximate fixed point property with applications. Fixed Point Theory Appl. 2012, 6 (2012). doi:10.1186/1687-1812-2012-6

12. Du, W-S: On approximate coincidence point properties and their applications to fixed point theory. J. Appl. Math. 2012, Article ID 302830 (2012). doi:10.1155/2012/302830

13. Du, W-S, He, Z, Chen, Y-L: New existence theorems for approximate coincidence point property and approximate fixed point property with applications to metric fixed point theory. J. Nonlinear Convex Anal. 13(3), $459-474$ (2012)

doi:10.1186/1029-242X-2012-206

Cite this article as: Du and Lakzian: Nonlinear conditions for the existence of best proximity points. Journal of

Inequalities and Applications 2012 2012:206

\section{Submit your manuscript to a SpringerOpen ${ }^{\circ}$ journal and benefit from:}

- Convenient online submission

- Rigorous peer review

- Immediate publication on acceptance

- Open access: articles freely available online

- High visibility within the field

- Retaining the copyright to your article 